\title{
Total Harmonic Distortion Reduction for Power Quality Improvement: A Review
}

\author{
Vishwaprakash Babu' ${ }^{1}$, Dr. M. Manikandan ${ }^{2}$ \\ ${ }^{1}$ Associate Professor, Department of Electrical and Electronics Engineering, Jyothishmathi Institute of Technology \& Science, Karimnager, \\ Telangana, India 505481 \\ ${ }^{2}$ Professor, Department of Electrical and Electronics Engineering, Jyothishmathi Institute of Technology \& Science, Karimnager, Telangana, \\ India 505481
}

\begin{abstract}
The non-linear load such as single-phase diode rectifier, inverters/converters, low voltage power supplies, SMPS and personal computers are exists in every industry. In all three-phase system the lowest and significant order of harmonic will be 5th harmonic after the fundamental. This harmonics increases losses in the form of heat dissipation and also contributes to eddy currents and core losses. Due to this effect, the power quality gets affected. In this paper a brief survey of harmonic mitigation techniques are presented which are used to mitigate power quality problems.
\end{abstract}

Keywords: Power Quality, Harmonics, harmonic mitigation

\section{Introduction}

In the recent year, present many different non-linear loads in the different kinds of industries. Due to the non-linearity of the loads it injects harmonics in the system and deteriorates the power factor of the entire system. The three kinds of harmonics will be generated that is positive sequence harmonics, negative-sequence harmonics and zero-sequence harmonics. The harmonic components have large current magnitudes. The current harmonic components such as 7 th, $13 \mathrm{th}, 19^{\text {th }}$ are positive-sequence harmonics and 5th, 11th, $17^{\text {th }}$ are negative-sequence harmonics is excessive in phase line which increase the THD (Total Harmonic Distortion) of the system. The zero-sequence harmonics current as 3th, 9th, 15 th is the triplen harmonics will flows through the neutral wire and may cause overheating on that wire. Huge loss in terms of time and money has made power quality problems a major anxiety for modern industries with non-linear loads in electrical power system.

\section{A. Motivation of Study}

Harmonic pollution is mostly common in low voltage side due to wide use of nonlinear loads, which is undesirable as it cause serious voltage fluctuation and voltage dip in power system. So it required to eliminate undesirable current and voltage harmonics and to compensate the reactive power to improve the performance and operation of the power system. The use of traditional passive filter in removing harmonics is not that much effective because their static action and no real time action or dynamic action is taken for the removal of harmonics. But the shunt active power filter on the other hand gives promising results when compared with conventional active and passive filters. This study basically shows the comparison between two current control strategy i.e. synchronous frame reference method and instantaneous active-reactive power method which is helpful to reduce the current harmonics.

\section{B. Objectives of the Review}

The main objectives of this review are

- To give a brief overview about the cause and effect of harmonics in power system

- To study different types proposed filter used to eliminate harmonics from the power system.

- To study and implement different control strategies already proposed for modeling of 3 phase shunt active power filter

- To model and simulate three phase shunt active power filter with different current control strategy in MATLAB/SIMULINK environment.

- To compare different control strategies based on FFT analysis (an important tool for harmonic behavioral analysis) for harmonic elimination in power system network.

\section{Source of Harmonics}

Harmonics are usually defined as periodic steady state distortions or deterioration of original voltage and/or current waveforms in power systems where frequency of harmonic wave is an integral multiple of fundamental frequency. Major sources of voltage and current harmonic generation in power system are

1) Controlling action of power electronic devices such as chopper, inverter etc. cause imbalance in power system leading to harmonic generation.

2) Non-linear load such as UPS, SMPS, battery charger.

3) Power electronic converter such as high-voltage directcurrent power converters, traction and power converters, wind and solar-powered dc/ac converters cause harmonic generation owing to their energy conversion and controlling action.

4) Heating material in ac/dc converters acts as a nonlinear load whose controlling action produces harmonics due to inherent property of high reactive power requirement.

\section{Effect of Harmonics}

Harmonics may cause interference and disturbance in power systems network. Some of the major problems include:

1) Harmonic currents present in the power system causes heating of equipment, such as transformers and 


\section{International Journal of Science and Research (IJSR) \\ ISSN (Online): 2319-7064}

Index Copernicus Value (2015): 78.96 | Impact Factor (2015): 6.391

generators and give huge copper loss.

2) In generators owing to multiple zero crossings of distorted current waveform causes voltage instability and voltage fluctuation.

3) Since frequency of harmonic current is different from that of fundamental may cause improper breaker and switch operation which is undesirable.

\section{Shunt Active Power Filter}

As the name depicts the shunt active power filter (SAPF) are connected in parallel to the power system network wherever a source of harmonic is present. Its main function is to cancel out the harmonic or non-sinusoidal current produce as a result of presence of nonlinear load in the power system by generating a current equal to the harmonic current but off opposite phase i.e. with $180 \mathrm{o}$ phase shift w.r.t to the harmonic current. Generally SAPF uses a current controlled voltage source inverter (IGBT inverter) which generates compensating current (ic) to compensate the harmonic component of the load line current and to keep source current waveform sinusoidal. Basic arrangement of SAPF is shown in figure 1 through block model.

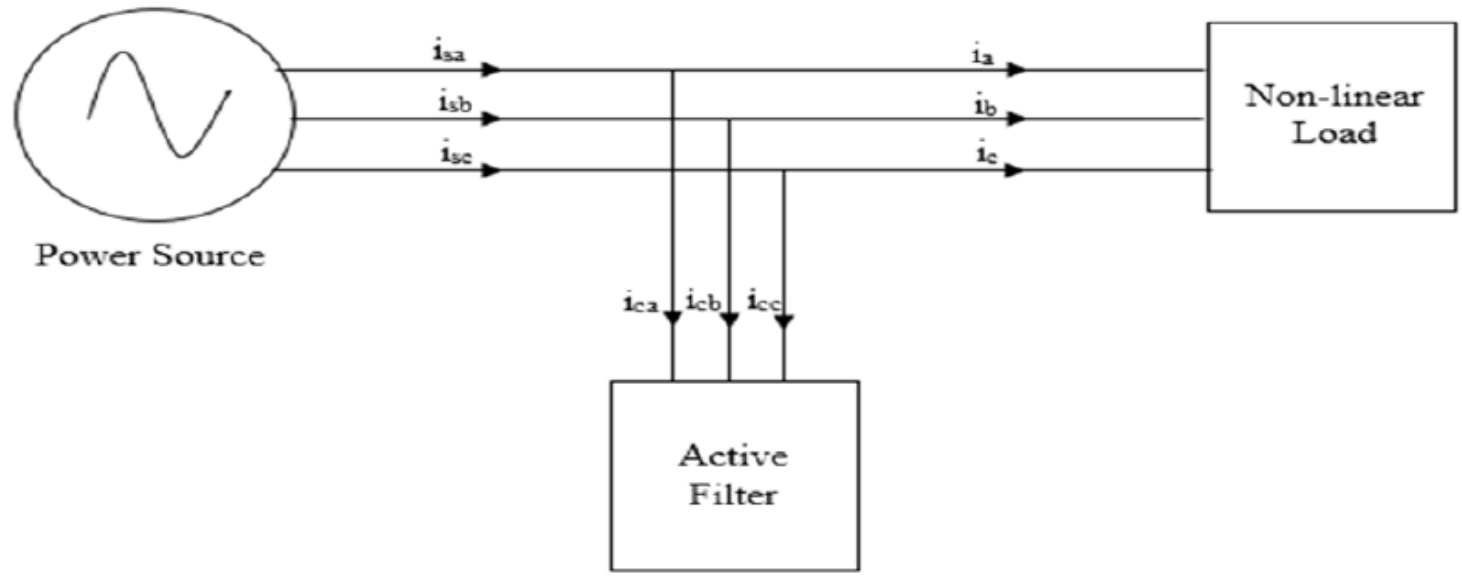

Figure 1: Shunt Active Power Filter

Compensating harmonic current in SAPF can be generated by using different current control strategy to increase the performance of the system by mitigating current harmonics present in the load current.

\section{Harmonic Mitigation Techniques with FACTS Devices}

Tejas Zaveri et al. [10] have proposed a Distribution STATIC COMPENSATOR (DSTATCOM) for balancing source currents, power factor correction and harmonic mitigation in three-phase, three-wire distribution system supplying delta connected load under various source voltage conditions. The control strategy applied to the DSTATCOM play a major role in its performance. A novel approach based on an improved instantaneous active and reactive current component (IARCC) theory is proposed for generation of three-phase reference currents for DSTATCOM. A threephase voltage source converter with a dc bus capacitor is employed as DSTACOM, which will track the reference currents in a hysteresis band scheme. The performance of DSTATCOM is evaluated under sinusoidal, unbalanced sinusoidal and unbalanced distorted source voltage conditions. The performance of the DSTATCOM using the proposed control strategy is demonstrated using simulation results in MATLAB/SIMULINK software. Simulation results demonstrate the feasibility of proposed scheme for the control of DSTACOM.

According to Mohammad H. Moradi et al.[11] different methods for voltage sag source location (upstream or downstream) based on various criteria such as energy, impedance, voltage or current is simulated and compared with each other. In this method the current (pre sag and during sag) is the only variable measured by relay/power quality (PQ) monitor. The performance of proposed method along with the mentioned methods above will be compared under symmetrical and asymmetrical faults on a sample network. This network is a largescale real regional network including transmission and sub-transmission levels, which was modeled by using PSCAD/EMTDC. The output data are processed via MATLAB codes. The results determine the accuracy and validity of each method and show good performance of the proposed method and its unique applicability in cases where only currents are recorded. This study will help utilities in operation and network planning

E. Najafi et al. [12] have proposed a new current mode controller to overcome the mentioned problem. The approach uses a fixed frequency current controller to maintain voltage levels in voltage sags (dips). This proposed was also simple and can be easily implemented by digitally. It has superior performance over conventional methods in terms of harmonic reduction in STATCOM output current. Another important factor for STATCOM effectiveness in sag mitigation is its sag detection method. This paper also introduced sag detection method based on Goertzel algorithm, which was both effective and simple for practical applications. The simulation results presented illustrate the superiority of the proposed controller and sag detection algorithm to be utilized in the STATCOM. Tejas Zaveri et al. [13] have discussed the mitigation of power quality disturbance in low voltage distribution system due to voltage swells using one of the powerful power custom devices namely Dynamic Voltage Restorer (DVR). The DVR normally installed between the source voltage and critical or

\section{Volume 6 Issue 7, July 2017 www.ijsr.net}




\section{International Journal of Science and Research (IJSR) \\ ISSN (Online): 2319-7064}

Index Copernicus Value (2015): 78.96 | Impact Factor (2015): 6.391

sensitive load. The new configuration of DVR has been proposed using improved d-q-o controller technique. The simulations are performed using Matlab/Simulink's SimPower Toolbox. The proposal is then implemented using 5KVA DVR experimental setup. The simulation and experimental results demonstrate the effective dynamic performance of the proposed configuration

T. K. Abdel-Galil et al. [15] have proposed a technique in which FACTS devices, power electronic devices and their switching control schemes are used for improving the power flow in the transmission network and hence improve the power quality and reliability of the low-voltage distribution network. The Distributed Static Compensator or DSTATCOM was a type of FACTS controller and has the function of reactive power compensation and harmonic mitigation. This paper discussed the use of synchronous detection algorithm for implementation of DSTATCOM for mitigation of harmonics.

Sandesh Jain, Prof.Shivendra Singh Thakur, Prof. S. P. Phulambrikar (2012) they discussed design and simulation of dynamic voltage restorer for improve power quality \& reduce the harmonics distortion of sensitive load. Passive filters can be placed either on the high voltage side or the converter side of the injection transformers. In DVR, filters are used to convert the inverted PWM waveform into a sinusoidal waveform. This can be achieved by eliminating the unwanted harmonic components generated by the VSI action. Higher orders harmonic components distort the compensated output voltage. The unnecessary switching harmonics generated by the VSI must be removed from the injected voltage waveform in order to maintain an acceptable Total Harmonics Distortion (THD) level. The performance of the proposed topologies and an improvement of suggested controller can be observed through simulation and experimental results. The THD and the amount of unbalance in load voltage are decreased with the application of DVR. The proposed system performs better than the traditional methods in mitigating harmonics and voltage sags. Priyanka K.Gaurkhede \& Vinod Kumar Chandrakar(2017) Non Linear Loads in the Power System are the Source of production of harmonics, due to the harmonics in system power quality get decreases and affect the load side as well as consumer side. Thus it is necessary to control the harmonics to improve the power quality of the system. STATCOM is used to recover the power Quality by dropping harmonics. The System is studied under different condition with Linear load \& Non-Linear Load harmonics of the system are studied. Under Steady State operation condition System performance is balanced but with the NonLinear load system harmonics increased. The harmonics get reduced by using STATCOM. Hence Power Quality issue (Harmonics) are reduces by using a device STATCOM.

Table 1: Total Harmonic Distortion of System with and without filter

\begin{tabular}{|c|c|c|c|}
\hline System & $\begin{array}{c}\text { System } \\
\text { without } \\
\text { SAPF }\end{array}$ & $\begin{array}{c}\text { System with } \\
\text { SAPF using } \\
\text { 'p-q' method }\end{array}$ & $\begin{array}{c}\text { System with SAPF } \\
\text { using 'd-q' method } \\
\text { in STATCOM }\end{array}$ \\
\hline$\%$ THD & $29.51 \%$ & $5.0 \%$ & $2.12 \%$ \\
\hline
\end{tabular}

\section{Conclusion}

In this paper, we have reviewed the mitigation techniques using FACTS devices of various PQ issues like harmonics voltage sag, very short and long interruptions, etc. Power system and its equipment is badly affected to this PQ issues like breakdown of information technology equipment or may be stoppage of all equipment, circuit breakers trip without being overloaded, automated systems stop for no apparent reason, electronic systems work in one location but not in another location. Most of the research highlight on product innovation and cost reduction. But few of them focuses on studying the PQ related issues are of most distress because of the extensive use of power electronic equipments. System without SAPF the \% of THD is $29.51 \%$, System with SAPF using 'p-q' method is $5.0 \%$ and System with SAPF using 'd-q' method in STATCOM is $2.12 \%$. Here I have intended to propose a proper change in perspective of $P Q$. The information obtained in the current study will be helpful to understand the mitigation techniques using FACTS devices of power quality problems in the electrical network.

\section{Directions For Future Research}

This paper contain the topic means compensate power quality problem have good scope as our power system is most affected by power quality problems because now a days there is no any technology available which is able to compensate or protect power qualities problem totally or fully, we only compensate certain part of power quality problem that's why at time to time researchers, research on this topic to how to compensate power quality problems. Now a days nonlinear loads are frequently used in our power system, it is also the major source of power quality issues. This paper focuses on to compensate voltage variation (sag, swell, etc.). It can also mitigate voltage dips and overvoltages, compensate reactive power of the load, unbalance in currents, and can compensate unbalance in load voltages. In future cost-effective mitigation techniques can be developed to mitigate multiple power quality problems simultaneously.

\section{References}

[1] Kenneth Holmberg, Roope Siilasto, Tarja Laitinen, Peter Andersson and Ari Jäsberg "Global energy consumption due to friction in paper machines", Tribology International, Vol. 62, pp. 58-77, 2013.

[2] Francois Martzloff, "Protecting Computer Systems against Power Transients", OCLC Systems \& Services, Vol. 6 No. 4, pp.17-21, 1990. Mitigation of Power Quality Problems Using FACTS Devices: A Review 261

[3] R. K. Rojin "A Review of Power Quality Problems and Solutions in Electrical Power System", International Journal of Advanced Research in Electrical, Electronics and Instrumentation Engineering, Vol. 2, No. 11, pp. 5605-5614, 2013

[4] Hingorani N.G., "Introducing custom power", IEEE Spectrum, Vol. 32, No. 6, pp. 41-48, 1995.

[5] Sandesh Jain, Shivendra Singh Thakur, \& 


\section{International Journal of Science and Research (IJSR) \\ ISSN (Online): 2319-7064}

Index Copernicus Value (2015): 78.96 | Impact Factor (2015): 6.391

S.P.Phulambrikar "Improve Power Quality And Reduce The Harmonics Distortion Of Sensitive Load" International Journal of Engineering Research and Applications (IJERA) Vol. 2, Issue 6, NovemberDecember 2012, pp.806-815 ISSN: 2248-9622

[6] Priyanka K.Gaurkhede\#1, Vinod Kumar Chandrakar "Reduction of Harmonics for Power Quality Improvement by using STATCOM" SSRG International Journal of Electrical and Electronics Engineering (SSRG-IJEEE) - volume 4 Issue 1January 2017 ISSN: $2348-8379$

[7] Chong Han, Zhanoning Yang, Bin Chen, Alex Q. Huang, Bin Zhang, Michael R. Ingram and Abdel-Aty Edris "Evaluation of Cascade-MultilevelConverterBased STATCOM for Arc Furnace Flicker Mitigation", IEEE Transactions On Industry Applications, Vol. 43, No. 2, March/April 2007

[8] K. A. Schwabe, P. W. Schuhmann, and M. Tonkovich "A Dynamic Exercise in Reducing Deer-Vehicle Collisions: Management through Vehicle Mitigation Techniques and Hunting", Journal of Agricultural and Resource Economics, Vol. 27, No. 1, pp. 261-268.

[9] S. Rahmani, Ab. Hamadi and K. Al-Haddad "A New Combination of Shunt Hybrid Power Filter and Thyristor Controlled Reactor for Harmonics and Reactive Power Compensation", IEEE Electrical Power \& Energy Conference, pp.1-6, 2009.

[10] Tejas Zaveri, B.R. Bhalja and Naimish Zaveri, "Load compensation using DSTATCOM in three-phase, three-wire distribution system under various source voltage and delta connected load conditions", Electrical Power and Energy Systems, Vol. 41, pp. 3443, 2012.

[11] Mohammad H. Moradi and Younes Mohammadi "Voltage sag source location: A review with introduction of a new method", Electrical Power and Energy Systems, Vol. 43 pp. 29-39, 2012.

[12] E. Najafi and A.H.M. Yatim "A novel current mode controller for a static compensator utilizing Goertzel algorithm to mitigate voltage sags", Energy Conversion and Management, Vol. 52, No. 4, pp. 1999-2008, April 2011,

[13] Tejas Zaveri, Bhalja Bhavesh and Naimish Zaveri "Control Techniques for Power Quality Improvement in Delta Connected Load using DSTATCOM",Electric Machines \& Drives Conference (IEMDC) IEEE International, pp.1397-1402, 2011

[14] N. Sudhakar, N. Rajasekar, S. Arun and A. Shanmuga Sundari, "Mitigation of EMI in DC-DC converter using analogue chaotic PWM technique", International Conference on Sustainable Energy and Intelligent Systems (SEISCON 2011), , pp.272-277, 2011. 262 Rajeev Kumar Chauhan \& J.P. Pandey

[15] T. K. Abdel-Galil, E.F. El-Saadany and M.M.A. Salama "Effect of New Deregulation Policy on Power Quality Monitoring and Mitigation Techniques", Transmission and Distribution Conference and Exposition, Vol. 1, pp.554-560, 2001.

\section{Author Profile}

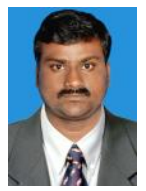

Vishwaprakash Babu graduated in B.Tech in Electrical, M.Tech (Industrial Engineering \& Management) He was born in Ieeja, Gadwal, Telangana. India, in 1981. He received his B.Tech. degree in Electrical Engineering from JNT University Hydarabad in 2002 and M.Tech. (Industrial Engineering \& Management) from JNT University Hydarabad in 2009. Presently, he is working as Associate Professor Jyothishmathi Institute of Technology \& Science Karimnager, Talangana, India He is having more than 14 years of teaching experience in the department of Electrical and Electronics Engineering. His current research interest includes Power System, Power Electronics and Power Quality Issues.

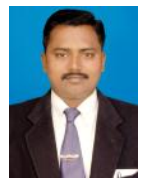

Dr. M. Manikandan graduated in B.E in Electrical, M.E(Power Electronics Drives). He was awarded Ph D in EEE He has 13 years of teaching experience and 7 years of research experience .He is a Member of IEI, ISTE and IAENG. He has Published 14 papers in International and National Level Journals Presently he is the Professor in EEE Department, Jyothishmathi Institute of Technology \& Science Karimnager, Talanguna, India His area of specialization is power system and power electronics. His research interests include application of soft computing techniques in power system problems, Power quality. 